\title{
A Kind of Scheme for Microgrid Protection
}

\author{
Chaohao Cai ${ }^{1, a^{*}}$, Zhigang Zhao, b and Tian $\mathrm{Hu}^{1, \mathrm{c}}$ \\ ${ }^{1}$ Shenyang Institute of Engineering, Shenyang 110136, China \\ a785133691@qq.com, b8809018@163.com, 'tonyhuangel@163.com
}

Keywords: Microgrid; Protection scheme; Compare of currents phase; Differential protection

\begin{abstract}
Microgrid protection is one of the crucial technologies of microgrid. In this paper, a new microgrid protection scheme was proposed, which is suitable for microgrid working in both grid-connected and island modes. We proposed a solution for the challenging problem in AC microgrid, as the limitation for fault current level, the effect on the protection by the change of power direction and the complexity of microgrid network structure .This paper also analyzed theory and practical application of the protection scheme proposed, and the validity and good performance of the protection scheme was validated.
\end{abstract}

\section{Introduction}

Microgrid is a small medium voltage and low voltage power network which is composed by many distributed power supplies and regional loads [1]. It can operate when connecting to the large grid and also can run in planned island mode. The microgrid should have perfect protection and control function $[2,3,4]$, in order to improve the power supply reliability of the load and utilization rate of the distributed power supply. For the moment, many countries have demonstration project of microgrid, microgrid protection is in research stage, and there is no unified standard. The function of microgrid protection is limited, for example, it is not suitable for the complex structure of microgrid, and it is not sensitive to high impedance ground fault protection. In this paper we use current phase comparison differential protection as feeder main protection, the protection scheme is more applicable to microgrid from the protection principle, and it also has higher sensitivity. In this paper, a backup protection scheme for microgrid was also proposed, which is composed of low voltage and directional elements.

\section{General Method of Microgrid Protection}

The literature [5] is an important document for microgrid protection. A protection scheme using digital relays with a communication network was proposed for the protection of the microgrid system, It used instantaneous current differential protection as feeder main protection, the two sampling absolute value of the differential current exceed the setting value ,the protection device act outlet tripping. Some papers take adaptive protection in microgrid such as literature [6], a centralized controller was required to store several sets of protection setting values. The microgrid would change to corresponding protection setting value in different running states. The protection need special communication network which covering the main part of the microgrid, we consider that this kind of protection is only applicable to microgrid which with small scale and simple structure, it will cause setting calculation difficulty in large scale microgrid, and this kind of protection belongs to the centralized protection, relatively easy to appear the entire microgrid operation accident. The literature [7] proposed to detect the fault and fault types by the conversion of the three-phase voltage of the microgrid to abc-dq changed. Some papers proposed the protection scheme based on negative sequence current component, it can be used in simple microgrid, but the setting calculation will be quite complicated in microgrid with complex structure. We also consider the method of using fault current component to form the protection, in order to reduce the influence of load current of differential protection. 


\section{Protection Scheme of Microgrid We Proposed}

Main Protection of Microgrid. As microgrid in Fig. 1, the preliminary simulation calculation is carried out in the literature [3], for example we proposed the Protection scheme and use it in this typical microgrid.

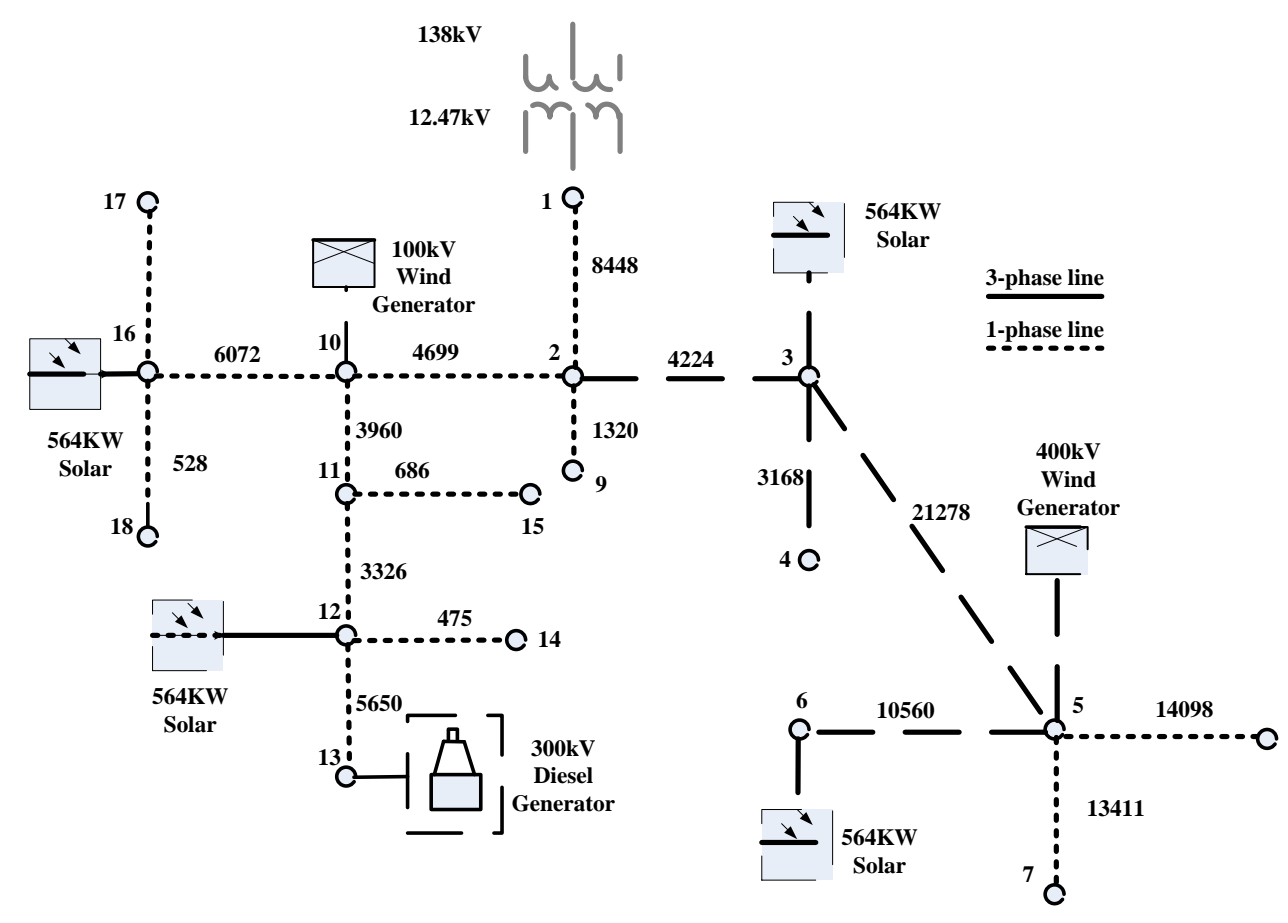

Figure 1. Structure of the typical microgrid

The main protection of microgrid main protection refers to the main transmission line of microgrid, as the main protection between the line 16 (the line between node 16 and node 10)and line 5(the line between node 5 and node 3 ), in this paper, the current phase comparison differential protection was used as the main protection of microgrid, the author proposed this kind of protection in literature [9], the protection algorithm is given as: make combination after take multiply pair wise with the three sample point value, protective action discriminate is as follow:

$$
i_{M 1} i_{N 1}+i_{M 3} i_{N 3}-i_{M 2} i_{N 2}=\frac{1}{2} I_{M} I_{N} \cos j \quad ? 0
$$

Take $i_{M 1} \sim i_{M 3}$ and $i_{N 1} \sim i_{N 3}$ as Data for every calculation, and the calculate window length is $4 * 5 / 3=6.67 \mathrm{~ms}$, the protection algorithm is simple, and the data window length is short, it is conducive to the protection for fast action. The simulation is below.

[t,x,Ibus] = sim ('ex03_263',[0 0.08])

cri=Ibus $(1,1)$

$\mathrm{s}=$ length $(0: 0.02 / 12: 0.08)$

for $\mathrm{n}=1: \mathrm{s}-2$;

$\operatorname{cri}(\mathrm{n})=\operatorname{Ibus}(\mathrm{n}, 1)^{*} \operatorname{Ibus}(\mathrm{n}, 2)+\operatorname{Ibus}(\mathrm{n}+2,1) * \operatorname{Ibus}(\mathrm{n}+2,2)-\operatorname{Ibus}(\mathrm{n}+1,1) * \operatorname{Ibus}(\mathrm{n}+1,2)$

end

$\operatorname{cri}(\mathrm{s}-1)=\operatorname{cri}(\mathrm{s}-2)$

$\operatorname{cri}(\mathrm{s})=\operatorname{cri}(\mathrm{s}-2)$

cri1 $=$ cri' $^{\prime}$

$[\mathrm{t}, \mathrm{x}, \mathrm{Ibus}]=\operatorname{sim}($ 'ex03_268',[0 0.08],[],[t,cri1] $)$

for $\mathrm{n}=1$ :length(cri)-2 

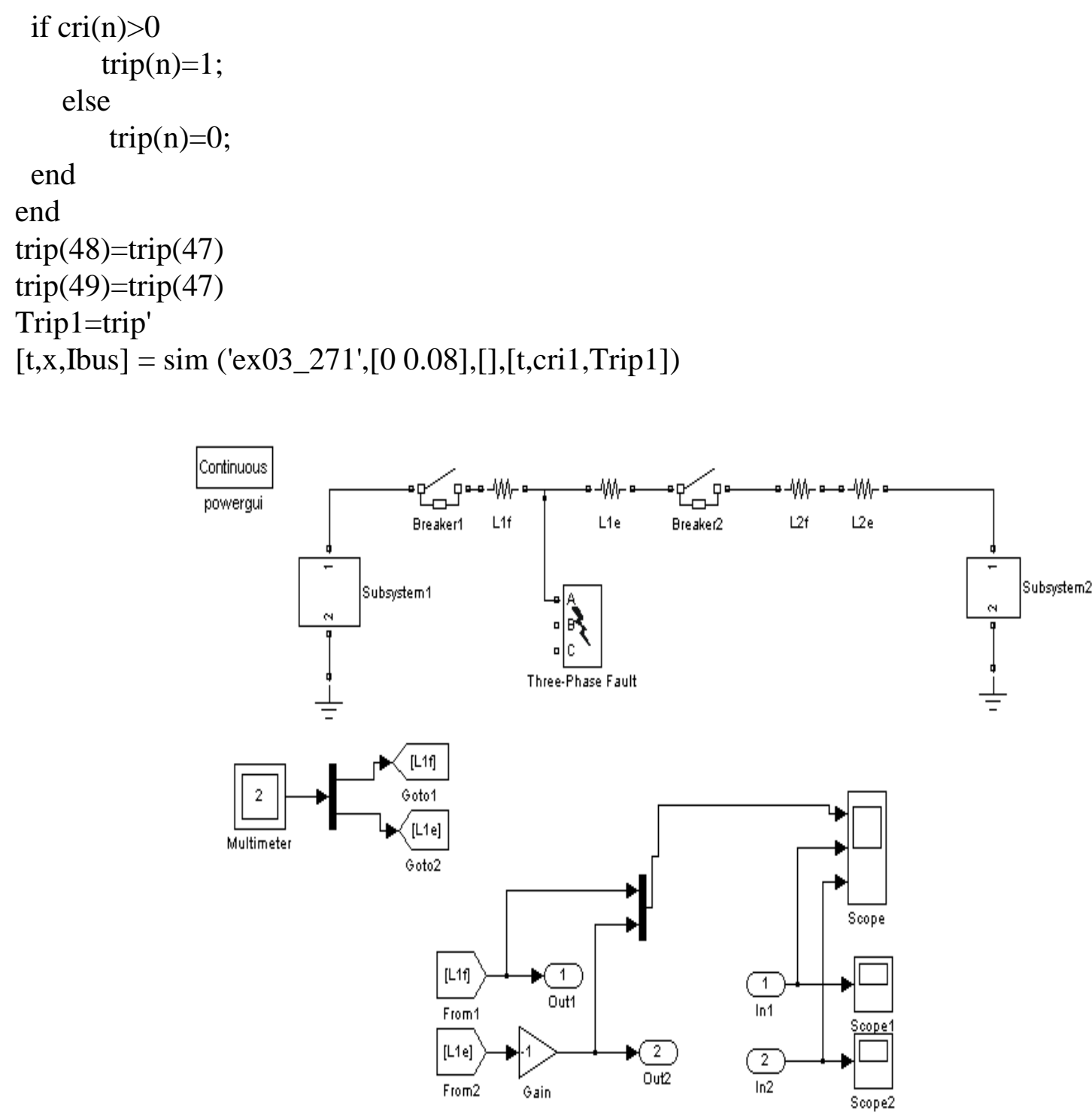

Figure 2. Simulation model of main protection

The protection used in this paper is based on the principle of the current phase on the two sides of the line [10]. From the point of view of the protection principle, the magnitude of the line current is not related to the action of protection. In practical applications, the effect of line current amplitude on protection is very small, so it is suitable for the complex microgrid, which can protect the microgrid in grid connected operation and isolated operation, and the protection setting value do not need to switch in these two ways. This protection is better than the general phase current differential protection; it is more suitable for the operation of microgrid current amplitude changes frequently.

The main protection of the proposed algorithm was applied to the main circuit of the microgrid. The Matlab/Simulink software was used in analysis and simulation. Given several Period line current of line 5 In the simulation, from 0 to 0.1 seconds system operat normally, short circuit fault happen began in 0.1 seconds. The influence of short circuit fault was considered, as the current was power frequency before the fault, the frequency of both sides of the fault was decreased, and the frequency was not synchronous, one side of the frequency was $49 \mathrm{~Hz}$, and the other side was $48 \mathrm{~Hz}$.

The sampling value curve of one phase current is presented at here (12 times per power cycle). In $0 \sim 0.1$ seconds, the effective value of the line flowing through the normal load current is about 29A, and the phase of the two sides of the line is reversed. Three phase short circuit occurs on the line in 0.1 second, the effective value of the current on both sides of the line is about $90 \mathrm{~A}$ and $45 \mathrm{~A}$, and both 
sides of the current are close to the same phase. The output value of the protection criterion (about -800 ) is shown at $0 \sim 0.1$ second in Fig. 3, the protective action discriminant is not established, The output value of the protection criterion is +3750 after 0.1 seconds, the protective action discriminant is established.

The output value of the protection criterion is not determined in a short time after 0.1 second. Fig. 3 shows the protection of the three consecutive set of action to set up the situation, the output result is 1 after 0.107 second, it means that short circuit fault signal, and it can be used to tripping out to clear the fault. And at $0 \sim 0.1$ seconds, the output result is 0 , the protection is reliable without action. It can be seen in the more serious fault conditions, the protection is still able to correct action.

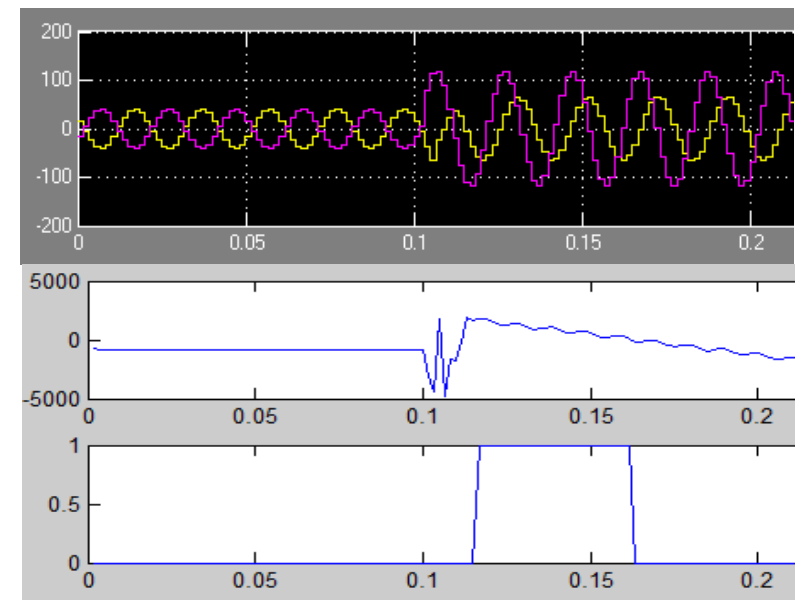

Figure 3. Waveform of single phase short circuit and main protection action

The output value of the protection criterion is not determined in a short time after 0.1 second. Fig. 3 shows the protection of the three consecutive set of action to set up the situation, the output result is 1 after 0.107 second, it means that short circuit fault signal, and it can be used to tripping out to clear the fault. And at $0 \sim 0.1$ seconds, the output result is 0 , the protection is reliable without action. It can be seen in the more serious fault conditions, the protection is still able to correct action. The above analysis is based on the single phase circuit analysis, but the protection is based on the phase connection, each phase of the trip is connected in parallel, so the protection is also suitable for react phase to phase short circuit fault.

Backup Protection of Microgrid. Backup protection of microgrid transmission line is only in the case of the main protection refused to operate or quit running, with more than 0.5 seconds of action delay, this paper intends to adopt the following methods:

When a short circuit fault occurs, the ring network in the microgrid is considered to form radial networks with multiple micro power sources. The points of system splitting should be set up properly, so as to keep power balance of each branch, and be close to the downstream of the transmission line.

A power directional element is arranged at the upstream side of each radial network near the upper reaches, as install a power directional element at the side of node 2 on line 3(between node 2 and node 3).

The low voltage protection device will be arranged on each line of the radial network, the low voltage components of each protection can be set at minimum operating voltage, e.g. 0.8 times of the rated voltage, the low voltage protection device will be arranged on each line of the radial network, the low voltage components of each protection can be set at minimum operating voltage, e.g. 0.8 times of the rated voltage. 


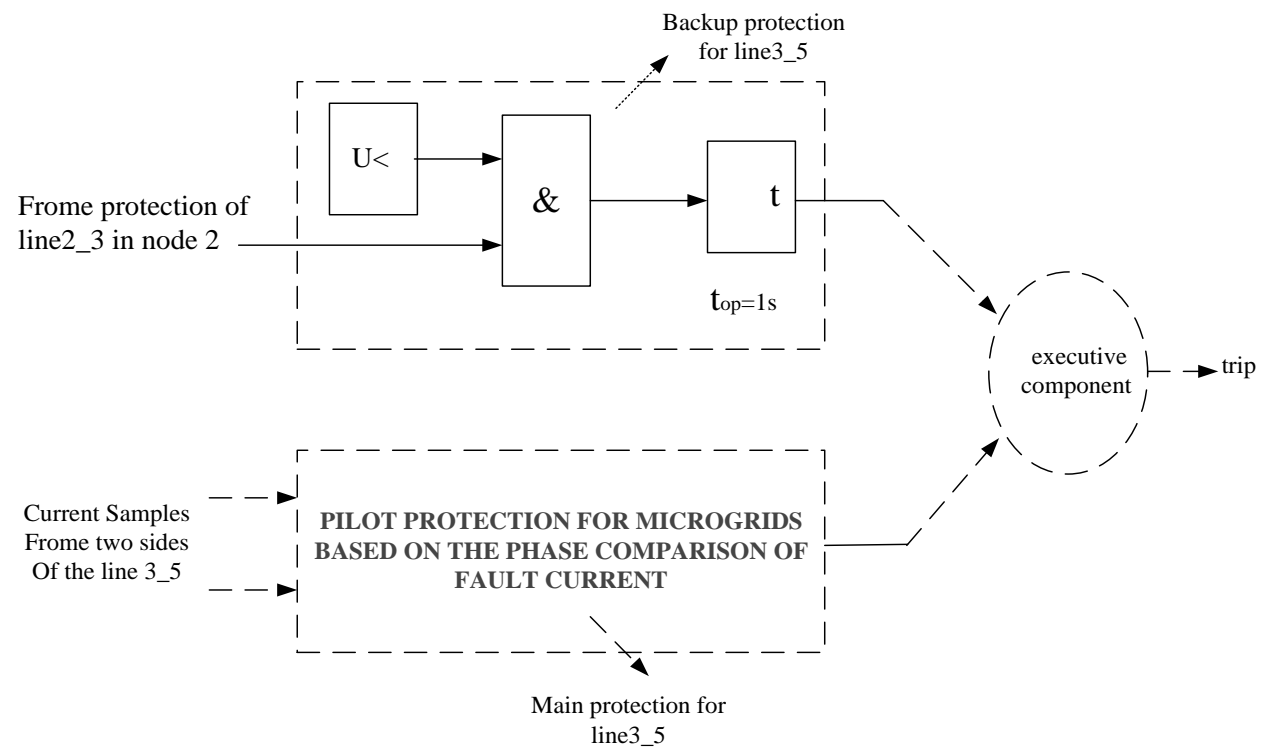

Figure 4. Protection diagram for line 3_5

Load-way Protection of Microgrid. The structure of the low voltage line (as line7 and line 4) of the microgrid user load is basically the same as the low voltage load line of the distribution network, residual current device should be used to protect the line, it has high sensitivity, it can be instantaneous cut on the ground short circuit fault or short circuit load line, and cut down leakage equipment, it make the fault will not affect the other parts of the microgrid. Because of the length of the paper, the protection of the other effects which involved in 3.2 will be discussed in the later article.

\section{Summary}

This paper had referred to the main information of the current microgrid protection; the characteristics of microgrid faults and feasibility of the existing schemes adopted by microgrid are analyzed. A new protection scheme for microgrid was presented. The protection scheme was based on the communication network, the protection scheme was simple and reliable, and had a small amount of calculation. It was suitable for the complex microgrid, which can protect the microgrid in grid connected operation mode or in isolated operation mode. This paper also put forward the specific algorithm of the protection, and the simulation program and model were established. The simulating result verified that the protection had better performance.

\section{References}

[1] Smart Grids E T P. Vision and Strategy for Europe's Electricity Networks of the Future [J]. European Commission, 2006.

[2] Wang X, Qi J, Hou Y, et al. Studies on fault analysis and protection configuration schemes in an isolated micro-grid[C]//PES General Meeting| Conference \& Exposition, 2014 IEEE. IEEE, 2014:1-5.

[3] H. Nikkhajoei and R. Lasseter, "Microgrid protection," in Proc. IEEE Power Engineering Soc. General Meeting, pp. 1-6, Jun. 2007.

[4] Sortomme E, Mapes G J, Foster B A, et al. Fault analysis and protection of a microgrid[C]//Power Symposium, 2008. NAPS'08. 40th North American. IEEE, 2008: 1-6.

[5] Sortomme E, Venkata S S, Mitra J. Microgrid protection using communication-assisted digital relays [J]. Power delivery, IEEE transactions on, 2010, 25(4): 2789-2796. 
[6] Hannu Laaksonen, Dmitry Ishchenko, Member, IEEE, and Alexandre Oudalov "Adaptive Protection and Microgrid Control Design for Hailuoto Island", IEEE Transactions ON SMART GRID, VOL. 5, NO. 3, MAY 2014

[7] Al-Nasseri H, Redfern M A, Li F. A voltage based protection for micro-grids containing power electronic converters[C]//Power Engineering Society General Meeting, 2006. IEEE, 2006: 7 pp.

[8] A. E. Emanuel, E. M. Gulachenski "HIGH IMPEDANCE FAULT ARCING ON SANDY SOIL IN 15kV DISTRIBUTION FEEDERS: CONTRIBUTIONS TO THE EVALUATION OF THE LOW FREQUENCY SPECTRUM", in IEEE Transactions on Power Delivery,Vol. 5, No. 2,April 1990,pp.276-284

[9] Cai C, Liu L, Gao Z. Pilot protection for microgrids based on the phase comparison of fault current $[C] / /$ Electricity Distribution (CICED), 2014 China International Conference on. IEEE, 2014: 1018-1022

[10]Zhang Baohui, Power system relay protection, China Electric Power Press, 2010.3 